\title{
Editorial
}

\section{JFDE Special Issue Glass}

Facade Design and Engineering is a multidisciplinary field that touches many other scientific disciplines. Glass is one of the key materials for building envelopes, and a strong scientific community has developed over the last decade. Designers love glass for its transparency. It is strong but brittle and very demanding in terms of engineering. We continuously see new innovative developments in terms of its climatic performance, structural possibilities, construction design and new applications. Reason enough to dedicate this special issue to the topic.

The issue would not have been possible without the contribution of our special editors Jan Belis and Christian Louter, who contributed through their outstanding editorial work and network. Most of the papers in this issue were carefully selected from of a number of invited submissions and conference papers of the COST Action TU0905 Mid-Term Conference, April 17+18 2013, Porec, (CRC Press/Balkema, Leiden) and subsequently subjected to the regular blind review process of the journal. Glass as a building material demonstrates the nature of the architectural discipline, where science and building practice are closely linked. Buildings are the live testing bed for scientific research and, at the same time, building practice formulates new research questions.

We found that many articles sent to us deal with this relation. Therefore we decided to introduce the new category 'Applied Practice' for certain journal paper contributions, which from now on can be found at the end of each issue. Although they do not need to be purely scientific, 'Applied Practice' papers will always discuss new developments, will have a clear structure and are subjected to the strict JFDE review process.

Façade Design and Engineering is a peer reviewed, open access journal, funded by The Netherlands Organisation for Scientific Research NWO (www.nwo.nl). We see 'open access' as the future publishing model. But it certainly requires new financial models which we will have to explore in the coming years. The introduction of 'Applied Practice' papers also serves a role here by linking the journal to a scientific as well as to a large professional audience. In this manner, it can fulfil its role to disseminate scientific knowledge. 
We are pleased to announce that we have been able to broaden the team around JFDE with Thaleia Konstantinou and Marjan Vrolijk as managing editors who will, along with the team members from IOS Press Amsterdam, certainly contribute to the quality of this publication.

The editors in chief, Ulrich Knaack and Tillmann Klein 